\title{
The Body Temperature has any Influence or Relation with Snoring
}

\author{
Muhammad Amir Aslam*, Muhammad Imran Qadir \\ Institute of Molecular Biology and Biotechnology, Bahauddin Zakariya University, Multan, Pakistan
}

*Corresponding Author: Muhammad Amir Aslam, Institute of Molecular Biology and Biotechnology, Bahauddin Zakariya University, Multan, Pakistan

\begin{abstract}
The objective of the present study was to know the influence of different body temperature on the snoring. The research with this title was not made by anyone. In this research project 210 students of University participated. For this purposes we check the body temperature of all these 210 students. The questionnaire based paper was prepared on which we put value of body temperature of different students in order to check the relationship between body temperature and snoring. We asked the question from students according to their body temperature whether they have snoring and they have given the answer according to their condition. In this way we got final result from our research. These 210 students belonged to Bahauddin zakariya university Multan Pakistan.
\end{abstract}

Keywords: snoring, body temperature, bhauddin Zakariya University

\section{INTRODUCTION}

The normal body temperature is $37 \mathrm{c}$ or $98.6 \mathrm{k}$. When body temperature increases from a normal value to high it is known as fever. The normal body temperature is necessarily required for normal functioning of body parts. The enzymes of organism work with high speed at optimum temperature. If temperature increases above optimum rang then enzymes starts to denature and normal functioning may decrease or stop. Similarly decrease in temperature stop the action of enzymes that can damage the different organs. Temperature measured by different method mainly used mercury thermometer which is heat sensitive. But now mostly digital thermometers are being used. The normal body temperature of every person has not same. In the $19^{\text {th }}$ century a German doctor set a $98.6 \mathrm{~F}$ as standard temperature as normal but recent study shows that different persons have different normal range of body temperature. The general value normal temperature for maximum people was $98.2 \mathrm{~F}$. The normal temperature of adult is from 97 to 99 . The babies and children normal temperatures have slightly higher than adult; it starts from 97.9 to 100 . The body temperature doesn't remain equal through whole day rather it fluctuate according activity of body and depends upon that what you have eaten. The normal body temperature value also depends on the gender and the age of person. The low body temperature is known as hypothermia. if temperature decrease from normal value for few hours then body organ start damage and it may cause the death of men. The temperature above from the normal range called hyperthermia. If orally measured temperature is above the 37.6 is known as fever. The fever is not always bad for health because when some germ invaded the body then body temperature increases to help the immune system of body. The fever caused in respons of several kind of infection, medicine and trauma or injury.

The snoring is the sound which is produced when breathing is obstructing during day or night sleep. When the tissue present in mouth in front of air way strikes to each other and produced unpleasant sound known as snoring. Snoring is initial stage but it may change into serious sleep apnea. The snoring may affect marriage life because bed partner may disturb his/her by snoring pollution.

\section{MATERIAL AND MeTHOD}

The body temperature can be measured by different parameter but here we used the digital thermometer. We just simply place the permanent probe of digital thermo meter in the mouth of person after few second they give the digital reading. And we note these reading on the paper which was prepared for research purposes. The questionnaire based paper was prepared on which we 
mention the body temperature of students that have snoring and also mention the body temperature of those students that have no snoring disorder.

There were 215 students participated in this project and we check body temperature of all these students by using digital thermometer. After measuring the body temperature of all the students we start to analyze whether there is some relation present between body temperature and snoring.

\subsection{Project Designed}

The purpose of present study was to find out relationship present between snoring and body temperature. The student of bahauddin zakariya university, Pakistan participated in this project. As we know $37 \mathrm{C}$ or 98.6 is normal body temperature but normal temperature of different persons have different normal body temperature. It means that body temperature shows some variation. That's why we designed this project for research purposes to find out relationship between snoring and body temperature.

\subsection{Statistical Analysis}

The statically work for undertook study was performed by MS EXCEL. BY using MS EXCEL we find out mean value, standard deviation and $P$ value (probability value) of collected data. The value equal or less than 0.1 is a significant $p$ value.

\section{RESULT AND DISCUSSION}

The total 210 students took part in this project. These 210 students have varied body temperature. There were 54 students who snore and their temperature was varied but we got the mean value of their varied body temperature. This variation was minimum because there is minimum standard deviation value. The mean value of body temperature of the students who snore at night was $94.7357 \mathrm{~F}$. The body temperature of 166 students was also show variation but this variation was minimum. The average value of body temperature of 166 students was $95.80 \mathrm{~F}$ and their 2.8 is standard deviation value. The standard and significant $\mathrm{p}$ value is equal to or less than 0.1 . But in our research the $P$ value is 0.74 which is less than significant $P$ value. This values show that there is no co-relation exist between body temperature and snoring but comparatively low body temperature showed some relation with Snoring and comparatively high body temperature have no relation with the snoring. The questionnaire based study was to find out relation between snoring and body temperature. And we find it low body temperature has slight relation with snoring but high body temperature have no any relation with snoring. There was no research made to co-relate the body temperature and snoring. This was our first attempts. And our result is given in table. The moreover in this project both male and female were included.

Table: The mean value of temperature + standard deviation + P value)

\begin{tabular}{|l|l|l|}
\hline Snoring (yes ) & Snoring (NO) & P value \\
\hline $\mathbf{9 4 . 7 3 5 7} \pm \mathbf{1 . 7 2 7 8}$ & $\mathbf{9 5 . 8 0 5 0 5} \pm \mathbf{2 . 6 1 3 4}$ & $\mathbf{0 . 7 4 3 7}$ \\
\hline
\end{tabular}

The present study has given the some kind of important outcome.

\section{CONCLuSion}

It was concluded from the present study that the average low body temperature and high body temperature have no any kind of relation with snoring. The low body temperature holder students those have snoring issue were small in numbers, therefore we can't say with confidence that low body temperature has some kind of relation with Snoring. The high body temperature also shows no relation with snoring. The students with high body temperature were large in numbers.

\section{REFERENCES}

[1] Qadir MI, Malik SA (2010) Comparison of alterations in red blood cell count and alterations in hemoglobin concentration in patients suffering from rectal carcinoma undergoing 5-fluorouracil and folic acid therapy. Pharmacologyonline, Nl 3: 240-243.

[2] Qadir MI, Noor A (2018) Anemias. Rare \& Uncommon Diseases. Cambridge Scholars Publishing. Newcastle, England. ISBN: 978-1-5275-1807-0.

[3] Qadir Many I, Javid A (2018) Awareness about Crohn's Disease in biotechnology students. Glo Adv Res J Med Medical Sci, 7(3): 062-064. 
[4] Qadir MI, Saleem A (2018) Awareness about ischemic heart disease in university biotechnology students. Glo Adv Res J Med Medical Sci, 7(3): 059-061.

[5] Qadir MI, Ishfaq S (2018) Awareness about hypertension in biology students. Int J Mod Pharma Res, 7(2): 08-10.

[6] Qadir MI, Mehwish (2018) Awareness about psoriasis disease. Int J Mod Pharma Res, 7(2): 17-18.

[7] Qadir MI, Shahzad R (2018) Awareness about obesity in postgraduate students of biotechnology. Int J Mod Pharma Res, 7(2): 14-16.

[8] Qadir MI, Rizvi M (2018) Awareness about thalassemia in post graduate students. MOJ Lymphology \& Phlebology, 2(1): 14-16.

[9] Qadir MI, Ghalia BA (2018) Awareness survey about colorectal cancer in students of M. Phil Biotechnology at Bahauddin Zakariya University, Multan, Pakistan. Nov Appro in Can Study, 1(3): NACS.000514.2018.

[10] Qadir MI, Saba G (2018) Awareness about intestinal cancer in university student. Nov Appro in Can Study, 1(3): NACS.000515.2018.

Citation: Muhammad Amir Aslam, Muhammad Imran Qadir, "The Body Temperature has any Influence or Relation with Snoring" International Journal of Research Studies In Biosciences (Ijrsb), Vol. 7, no. 7, pp. 1-3, 2019. http://Dx.Doi.org/10.20431/2349-0365.0707001

Copyright: (C) 2019 Authors. This is an open-access article distributed under the terms of the Creative Commons Attribution License, which permits unrestricted use, distribution, and reproduction in any medium, provided the original author and source are credited. 